\title{
Introduction of Abnormal Combustion in Hydrogen Internal Combustion Engines and the Detection Method
}

\author{
Jiahui Liu* \\ North China University of Water Resources and Electric Power, Zhengzhou, Henan 450045, China \\ Received January 28, 2022; Accepted February 13, 2022; Published February 26, 2022
}

\begin{abstract}
As a clean, environmentally friendly and renewable energy source, hydrogen as an alternative engine fuel can greatly reduce atmospheric pollution and alleviate the shortage of oil resources, and is the most promising alternative fuel for vehicles among new fuels. However, due to its fast combustion rate and wide ignition limit, hydrogen often shows abnormal combustion phenomena (such as pre-ignition, backfire and knock), when it is used in the engine, thus affecting the performance and normal use of engines. In this paper, the advantages and disadvantages of hydrogen as an alternative fuel for the engine are summarized according to the characteristics of hydrogen. On this basis, the mechanism, influence factors and harm of abnormal combustion in the hydrogen internal combustion engine are analyzed and summarized, which provides a theoretical basis for solving abnormal combustion problems. Finally, several commonly used abnormal combustion detection methods are summarized.
\end{abstract}

Keywords: Hydrogen internal combustion engine; Abnormal combustion; Detection method; Clean energy

\section{Introduction}

Energy plays an equally important role in the economic development of all countries in the world, and is an important measure of a country's comprehensive national power, economic development strength, people's basic living and social and cultural civilization level and its essential embodiment. The most widely used conventional energy sources in the global energy industry today are coal, oil, natural gas and other fossil fuels, which have greatly contributed to the progress of socio-economic. With the rapid development of global society and economy, the per capita energy consumption level has been rising significantly and rapidly. People are increasingly dependent on energy in their normal production activities and daily life, and energy plays an increasingly significant role and importance productivity in developed countries [1]. Most of the traditional energy sources such as coal, oil, natural gas and other fossil energy sources are non-renewable. Excessive exploitation and use will reduce energy storage, and the low efficiency of recovery and conversion of traditional conventional energy will cause energy consumption and waste in the conversion process. Traditional energy also causes a lot of pollution to the environment. These pollutants can directly enter our body through human breathing, which also causes harm to human physical and mental health.

As China's population and economy continue to grow and society continues to develop in recent years, the transport industry is gaining momentum and the automotive 
industry is growing rapidly. Although the popularity of the automobile has brought great convenience to people's lives, the problems of pollution and the consumption of oil resources due to exhaust emissions are also becoming more and more serious, so the search for renewable and clean energy sources to replace traditional petroleum-fueled vehicles has become a priority in the automotive sector. The development of clean and non-polluting alternative energy sources has become an inevitable trend, which has led to the transformation of the traditional automotive industry and the development of clean energy vehicles, which has also led to the development of hydrogen-fueled engines.

Therefore, this paper analyzes the advantages and disadvantages of hydrogen as an alternative fuel for vehicles, summarizes several common abnormal combustion phenomena in hydrogen internal combustion engines, lists their generation mechanisms, influencing factors and hazards, and finally summarizes several methods for detecting abnormal combustion in engines, in response to this current situation.

\section{Properties of Hydrogen as a Fuel}

Hydrogen as a fuel is the most promising alternative fuel for vehicles among all new fuels due to its high combustion efficiency, zero emissions and renewability [2]. The value of hydrogen energy applications has been widely recognized worldwide and there has been significant progress in its use. The continuous development of hydrogen storage technology has led to the use of hydrogen in a wide range of applications such as transportation, various engines, fuel cells and power stations.

Hydrogen is a clean and renewable energy source and does not contain $\mathrm{CH}, \mathrm{CO}$ or carbon particles in its emissions during combustion in engines. It is considered as a good solution to the problem of environmental pollution from conventional engine emissions [3]. Hydrogen can be used as an alternative engine fuel for the following reasons [4].

(1) Hydrogen burns quickly with high thermal efficiency.

(2) Hydrogen has a wide ignition limit and a wide combustible range, allowing for thin combustion and improved economy, while reducing the maximum combustion temperature and significantly reducing $\mathrm{NO}_{\mathrm{x}}$ emissions.

(3) Hydrogen has good diffusion performance. The diffusion coefficient of hydrogen is 12 times that of gasoline, which can be mixed more fully with air during premixed combustion and help combustion.

(4) The low ignition energy of hydrogen makes it less prone to misfires and reduces the cyclic changes in the cylinder. But it is also prone to abnormal combustion phenomena such as premature ignition and backfires, when it is ignited by hot exhaust gases and hot surfaces.

(5) Hydrogen has a higher ignition point in general. Engines can use a larger compression ratio, thus increasing the thermal efficiency of combustion.

\section{Common Abnormal Combustion}

\section{Premature Combustion \\ Mechanisms of Generation}

Early ignition means that before the normal ignition of the spark plug, the mixture in the cylinder is ignited by the higher temperature of the incandescent point. As the 
mixture is heated in the intake and compression process for a long time by the incandescent surface, the ignition area is also larger. Once ignited, the flame spreads quickly and the pressure rise rate is also larger. So the compression stroke at the end of the negative work is very large and increases the heat dissipation to the cylinder wall, which further promotes the incandescent point temperature rise and earlier ignition mixture [5]. Because of the low ignition energy of hydrogen and hydrogen flame propagation speed, hydrogen internal combustion engines are more prone to pre-ignition phenomenon. Generally speaking, the hot spots in the cylinder that cause pre-ignition are the spark plug insulator, electrode, exhaust valve and some deposits in the cylinder. Preignition is likely to occur in the external mixture formation method of hydrogen internal combustion engine. It is more likely to occur at the high compression ratio of high load.

\section{Influencing Factors}

The main factors affecting the pre-ignition of the engine are the compression ratio of the mixture, the engine speed, the temperature of the mixture when entering the cylinder through the intake pipe, the intake and exhaust gas distribution phase and the spark plug [6]. As the compression ratio increases, the temperature of the combustible mixture in the compression process will also continue to rise, resulting in the heat of the hot surface of the cylinder is not easy to dissipate and maintain a higher temperature. Therefore, the mixture into the cylinder is more likely to be ignited by the high temperature hot spot, increasing the tendency of pre-ignition. The higher the temperature of the hydrogen air mixture entering the cylinder, the more likely it is to ignite prematurely by the hot exhaust gas or hot surface in the cylinder. Because the ignition energy of hydrogen is low, the higher the temperature of the mixture, the higher the energy, and the easier it will be ignited. Increasing the overlap angle of the inlet and exhaust valves is conducive to removing the residual exhaust gas in the cylinder, increasing the fresh charge into the cylinder, which is conducive to reducing the heat load in the cylinder, the temperature of the combustion chamber wall and the tendency of preignition. But the overlap angle of the inlet and exhaust valves should not be too large, it may cause some gas backflow phenomenon. The spark plug in the compression and work stroke will absorb the heat generated by the combustion of the mixture (known as the hot surface). Under high temperature conditions, part of the lubricating oil volatilizes and adheres to the surface of the spark plug to form carbon, and the heat is not easy to dissipate. The difference in the structure and material of the spark plug will affect its thermal conductivity. The worse the thermal conductivity, the easier it is to cause premature ignition.

\section{Hazards}

When premature ignition is relatively mild, it increases the noise of the hydrogen internal combustion engine and causes a slight vibration of the hydrogen internal combustion engine. In general, premature ignition will cause the hydrogen internal combustion engine to stop running, affecting the normal operation of the vehicle. In severe cases, this may cause damage to components such as intake pipes, spark plugs and cylinders.

\section{Backfire}

Mechanisms of Generation 
Backfire is a phenomenon where the hydrogen-air mixture in the intake port is ignited prematurely before the intake valve has been closed. There are several different views on the mechanism of backfire. Some researchers believe that the flame of the unburned hydrogen gas in the cylinder ignites the combustible mixture in the intake port, but most believe that the backfire is caused by the high temperature residual exhaust gas in the combustion chamber and hot spots in the cylinder [7]. When the intake valve is first opened, the backfire is mainly caused by the high temperature exhaust gas, afterburning mixture and high temperature hot spots. When the intake valve is almost closed, the backfire is mainly caused by the continuous advance of pre-ignition.

\section{Influencing Factors}

Backfire is a type of abnormal combustion, where combustion occurs only under certain conditions. The following conditions are required for backfire to occur in the intake port: Firstly, there must be a suitable concentration of hydrogen in the intake port. Secondly, there must be a high temperature exhaust gas in the vicinity of the intake valve that is capable of igniting the hydrogen. The analysis of the high temperature exhaust gas includes the concentration and temperature of the exhaust gas and its location in the intake port. These parameters are closely related to the occurrence of backfire, so all the structural factors and operation factors that can affect the concentration, temperature of the exhaust gas and the change of the position of the exhaust gas in the intake are factors affecting the backfire. Backfire is related to the combustion rate and the concentration of the mixture. If the mixture is too lean, the combustion rate will be slow and the combustion of the mixture will continue until the exhaust gas end. When the intake valve is opened, the still-burning mixture can easily ignite the mixture in the intake port. [8].

\section{Hazards}

When the backfire phenomenon is slight, the noise of hydrogen internal combustion engine will increase rapidly or the intake port will misfire locally. In general, the hydrogen internal combustion engine cannot operate normally. In serious cases, the temperature and pressure in the intake port are too high, and the fresh charge cannot enter, causing the engine misfire and even the damage of the intake port and hydrogen supply system.

\section{Knock}

\section{Mechanisms of Generation}

The cause of knock can be attributed to the spontaneous combustion of the final combustion mixture. Before the ignition of a hydrogen internal combustion engine, the mixture is spontaneously combusted at a distance from the flame before the flame front surface reaches it. After the spark ignition, the flame propagates forward at the normal speed propagation rate $(30 \sim 70 \mathrm{~m} / \mathrm{s})$, making part of the final combustion mixture in the final combustion position further compressed and thermally radiated. It accelerates the prior reaction and releases some heat, making the temperature of the final combustion mixture rise continuously. So, before the normal flame arrives, the most suitable part of the final combustion mixture inside has already appeared one or more flame centre, resulting in flame from these centres to $100 \sim 300 \mathrm{~m} / \mathrm{s}$ (slight knock) to $800 \sim 1000 \mathrm{~m} / \mathrm{s}$ or higher rate (strong knock accompanied by shock waves) propagation and rapid combustion of the final mixture of gas burned out. Therefore, the phenomenon of knock is the final combustion mixture of spontaneous combustion phenomenon [9]. 


\section{Influencing Factors}

The main operating factors affecting knock are ignition advance angle, speed, load, mixture concentration and combustion chamber deposits. The main structural factors are cylinder diameter, spark plug position, cylinder head and piston material, and combustion chamber structure. In order to analyze the effects of various factors on knocking more concisely and clearly, two times are defined. The time required from the flame centre to the normal flame propagation to the final combustion mixture is $t_{1}$, while the time required from the formation of the flame center to the spontaneous combustion of the final combustion mixture is $t_{2}$.

Operating factors [10]:

(1) Ignition advance angle: With the increase of ignition advance angle, the time $t_{1}$ from flame center formation to flame propagation to the whole combustion chamber decreases. As the ignition advance angle increases, the pressure in the cylinder increases, the extrusion effect on the final fuel mixture increases, the temperature increases, and the delay period $t_{2}$ of the final fuel mixture decreases. According to the test, within the range of the practical ignition advance angle, the decrease of $t_{2}$ plays a decisive role, so the knock tendency increases with the increase of the ignition advance angle.

(2) Speed: With the increase of rotational speed, the propagation speed of flame increases and $t_{1}$ decreases. As the rotational speed increases, the charge coefficient decreases, the pressure in the cylinder decreases, $t_{2}$ increases, and the knock tendency increases.

(3) Load: At a certain speed and when the throttle is closed (i.e., the load is reduced), the residual exhaust gas coefficient increases, the in-cylinder pressure drops, $\mathrm{t}_{2}$ increases, and the propensity for deflagration decreases.

(4) Mixture concentration: The change of the mixture concentration will affect the flame propagation velocity and the ignition delay period of final combustion mixture. When the excess air coefficient is 0.8 to 0.9 , the flame propagation speed is the fastest and $t_{1}$ is the smallest, but the ignition delay period $t_{2}$ of the final combustion mixture is also the smallest. The test shows that the reduction of $t_{2}$ plays a decisive role, and thus when the excess air coefficient is 0.8 to 0.9 , the knock tendency is the largest. Too thick or too thin mixture of gas can reduce the tendency of knock.

(6) Combustion chamber deposits: During engine operation, a layer of deposits, generally known as carbon, is produced on the walls of the combustion chamber. The temperature of the carbon deposit is higher. The intake compression process constantly heats the mixture, and the deposit is a poor conductor of heat, therefore increasing the temperature of the final combustion mixture. The deposit itself occupies a certain volume, therefore increasing the compression ratio of the engine. In summary, the presence of deposits makes the knock tendency increased.

Structural factors [11]:

(1) Cylinder diameter: When the diameter of the cylinder increases, the propagation distance of the flame becomes longer, that is, $t_{1}$ becomes longer. As the ratio of the cooling area of the combustion chamber to the volume means that the surface to volume ratio decreases, the heat dissipation area per unit volume decreases, and the temperature increases. So, $\mathrm{t}_{2}$ decreases and the knock tendency will increase.

(2) Spark plug position: Spark plug position will affect the flame propagation distance and also affect the final combustion mixture in the cylinder, thus affecting the temperature of the final combustion mixture. For example, the spark plug is located in the 
exhaust valve is the least likely to cause knock. But if the distance from the intake valve is too large, then the spark plug gap in the exhaust gas is not easy to remove, and the spark plug will affect the stability of the engine running under low load.

(3) Cylinder head and piston material: The thermal conductivity of cylinder head and piston will affect the tendency of knock. Aluminum alloy has good thermal conductivity, so using aluminum alloy piston and cylinder head can inhibit the occurrence of knock and improve the compression ratio of engine.

(4) Combustion chamber structure: Combustion chamber structure is the most important structural parameter affecting knock. The shape of the combustion chamber will affect the flame propagation distance, turbulence intensity, heat dissipation to the cooling water and the number and temperature of the final combustion mixture. Any combustion chamber structure that allows for a shorter flame spread distance, higher turbulence and flame spread rate will help to reduce the knock tendency.

\section{Hazards}

(1) Engine overheating: When bursting into flames, the destruction of the boundary layer, cylinder head, the piston top surface temperature rise. Combustion chamber local overheating will cause surface ignition, thus further overheating, which eventually leads to light alloy cylinder head, piston softening, melting or burning. Local overheating in the cylinder will also cause high temperature decomposition of combustion products and thermal decomposition of the oil film on the cylinder wall. The reoxidation of the decomposed products is incomplete, resulting in exhaust smoke.

(2) Increased stress on parts: During knock, the pressure rise rate and the maximum combustion pressure both rise, making it easy to damage the stressed parts.

(3) Output power (i.e., thermal efficiency is reduced): Knock will lead to a sudden increase in local pressure and temperature in the engine cylinder, and it is too late to make the cylinder pressure equilibrium. The chemical reaction rate is greater than the rate of gas expansion, and thus will produce a pressure wave. When the shock wave hits the cylinder wall, it will destroy the laminar boundary layer, thus increasing the heat transfer coefficient and the cooling loss and reducing the output power. At the same time the thermal efficiency decreases due to the increased cooling losses and the appearance of carbon slag as a combustion product.

(4) The pressure wave generated by knock damages the oil film and cooling water film on the inner and outer surface of the cylinder wall, resulting in accelerated wear of parts [12].

\section{Abnormal Combustion Detection Methods}

In the study of engine fault diagnosis, the detection signals are mostly vibration signals, speed fluctuation signals, sound intensity signals, oil parameters, pressure signals, temperature signals and image signals. Most of the signals are processed using amplitude domain analysis, frequency domain analysis, fractal geometry, neural network, wavelet analysis, and combinations of these methods [13]. When abnormal combustion occurs, there may be macroscopic phenomena such as vibration, noise increase and temperature rise, and microscopic changes in the ion current signal, based on which different methods can be used to detect abnormal combustion. 


\section{Ion Current Method}

The mixture in the cylinder will produce a large number of charged particles such as free electrons, positive and negative ions and free radicals in the combustion process of spark ignition, fire core formation and flame propagation. Because they exist in the flame front area and burned area, the gas has certain conductivity. When a DC bias voltage is added to the two poles of the spark plug, an electric field is formed in the spark plug gap, with positive ions moving in the direction of the cathode and electrons and negative ions moving in the direction of the anode, forming a spark plug ion current [14].

In the paper [14], for example, a spark plug type ion current sensor was installed in a turbocharged PFI engine and the ion current signal was compared with the cylinder pressure signal and combustion characteristic values under different combustion conditions. By analyzing the ion current waveform, misfire cycles caused by spark plug failure to ignite or injector failure to inject fuel or lean mixture could be identified, respectively. The relationship between the ion current signal and the pre-ignition cycle was further analyzed experimentally. When the normal combustion cycle occurs, the ion current signal is generated in the order of the 1st peak - charging disturbance, 2nd peak discharging disturbance, 3rd peak - ion current signal. But in the pre-ignition cycle as shown in Figure 1, the ion current signal generation order has changed significantly, when the spark plug ignition accumulation occurs (generate the 1st peak - charging disturbance signal). Due to the pre-ignition phenomenon in the cylinder and the mixture produces spontaneous combustion, the ion current signal is generated in the early stage of spontaneous combustion. As the cylinder pressure rises, the cylinder temperature rises and the ion current signal strength rises (3rd peak - early ignition ion current signal). The duration of the pre-ignition ion current signal $t_{d}$ is also significantly greater than the 1 st and 2 nd peak signals. The pre-ignition ion current signal $t_{d}$ value detected in this test is $25^{\circ}$. Therefore, for this engine, when ion current is used to detect pre-ignition, preignition is considered to have occurred when the $t_{d}$-value is greater than $20^{\circ}$. The analysis in this paper shows that the ion current method can detect the occurrence of preignition very well.

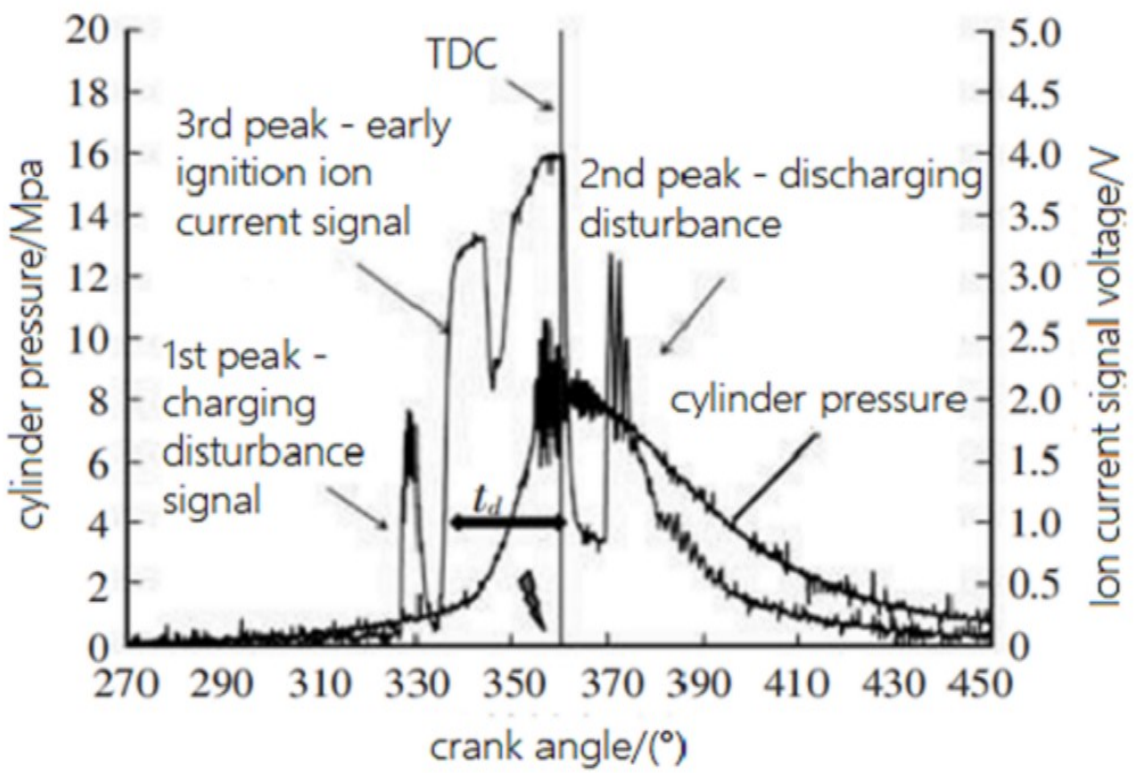

Figure 1. Schematic representation of ion current signal detection for pre-ignition [14] 
The ion current method can also detect the occurrence of knock. When knock occurs, the pressure wave generated by the knock propagates repeatedly at a high frequency in the cylinder, causing the local gas density in the cylinder to vibrate at a high frequency. In the combustion zone, the ion and free electron density in the gas also vibrates and changes. Thus, the pressure wave caused by the knock is superimposed on the spark plug ion current signal, and the frequency characteristics of the knock pressure wave can be obtained by a reasonable analysis of the spark plug ion current signal [15]. The literature [15] compares the effect of using the ion current method and the body vibration method for detecting engine detonations. It can be seen from Figure 2 that there are obvious differences between the ion current signals and vibration signals of the body under knock and non-knock conditions. The ion current signals in knock and non-knock conditions are smooth and regular, while the ion current signals in knock conditions are not smooth with superposition of high-frequency signals on the waveform. Similarly, the vibration amplitude of the body in the condition of no knock is small, but the vibration signal of the body in the condition of knock appears obvious large oscillation.

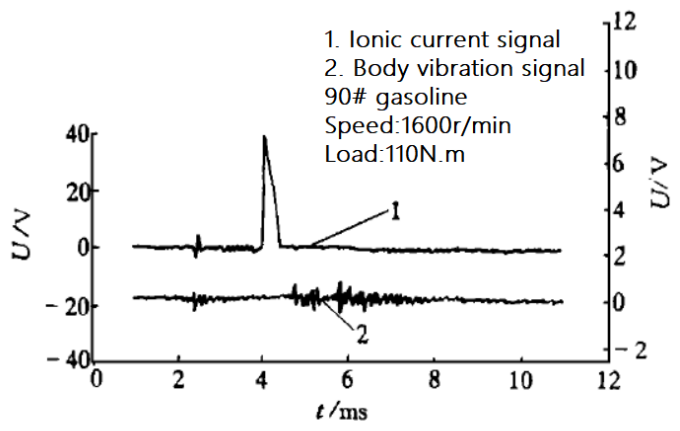

(a) non-detonating cumbustion

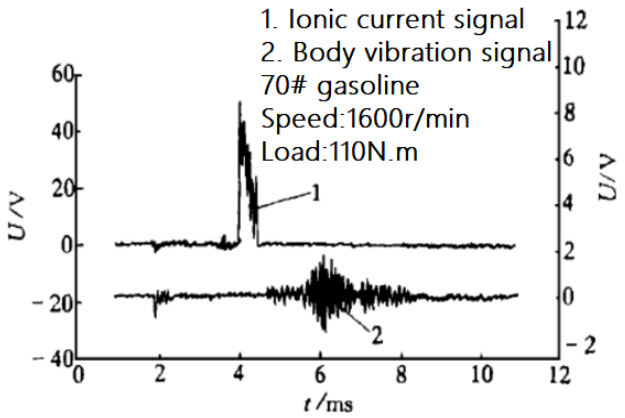

(b) detonating combustion

Figure 2. Without and with knock signal [15]

The ion current method is an emerging technology that is completely different from the traditional body vibration method. Compared to the body vibration method, it has the advantages of simple signal processing, accurate measurement and low cost, making it a new technology with great market potential.

\section{Body Vibration Method}

The body vibration method uses vibration sensors to detect detonations. During a knock, as the pressure wave is reflected by the cylinder wall, it causes the engine block to vibrate and the magnitude of this vibration varies depending on the position of the engine block. The frequency characteristics of the burst pressure wave can be obtained through a reasonable analysis of the vibration sensor signal at the appropriate location on the engine block. A vibration-based pre-ignition and knock detection system and its detection method can be used [16] to differentiate between pre-ignition and normal knock, depending on the vibration range of the two. This detection system includes vibration sensor and controller. The vibration sensor is mounted on the engine for detecting the vibration signal within a specific crankshaft angle range of the engine, and the detected vibration signal will be transmitted to the controller. The controller calculates and records the peak magnitude of the combustion cycle vibration signal and the phase corresponding to the peak. The vibration signal is used to determine whether pre-ignition and knock have occurred. The specific steps for the detection using this system are: 
(1) Pre-calibrate the engine and calibrate the knock threshold and pre-ignition threshold.

(2) Calculation of the vibration signal over a specific range of crankshaft angles, filtering of the signal and calculation of the peak and phase of the signal oscillation.

(3) Comparison of the detected peak and phase with the pre-calibrated knock threshold and pre-ignition threshold.

(4) Comparison of the detected peak and phase with the pre-calibrated knock threshold and pre-ignition threshold.

(5) This system detects pre-ignition and knocks based on vibrations in a simple and easy to use way, and is simple to operate and can be used in real vehicles without the need for additional equipment.

\section{Wide Domain Oxygen Sensor Method}

On Board Diagnostics (OBD) systems require the ability to monitor the components or systems that cause emissions exceedances. It is therefore of great practical value to study abnormal engine combustion in OBD systems and to analyze the emission status through the oxygen sensor signal. While conventional step-type oxygen sensors do not detect sudden changes in oxygen concentration under lean mixture conditions due to their non-linear output characteristics, the Universal Exhaust Gas Oxygen Sensor (UEGO) can measure air-fuel ratios between 10 and 20 in an infinite manner. As a result, the use of wide area oxygen sensors in recent years in lean-burn engines has made it possible to detect abnormal cylinder combustion conditions at full operating conditions.

Qi et al. [17] actively and rapidly adjusted the fluctuation range of closed-loop fuel regulating factor under specific working conditions to quickly change the exhaust gas composition of the exhaust system, and calculated the voltage jump frequency and jump amplitude of the oxygen sensor within a reasonable sampling interval to test the response performance of the voltage signal of the oxygen sensor. Dong et al. [18] designed a natural gas engine oxygen sensor fault simulation system with the technical support of LabVIEW software, and analyzed the influence of the oxygen sensor fault on engine power economy and various emission indicators. Fang et al. [19] studied the use of Bosch LSU ADV wide domain oxygen sensor with fast transient response characteristics to measure oxygen concentration in the exhaust pipe in real time to detect abnormal combustion conditions in the cylinder by identifying different abnormal combustion phenomena and determining abnormal combustion causes through different mutation values on the signals of the wide domain oxygen sensor.

The literature [19] shows that abnormal oxygen sensor signal waveforms, if not caused by engine control strategies under certain special operating conditions, generally indicate abnormal engine combustion and a fault in the associated system. These faults cause abnormal combustion of the mixture in the cylinder, which in turn causes the oxygen content in the exhaust to vary and the signal waveform of the oxygen sensor to become abnormal. For fuel injection system, ignition system faults and vacuum leaks caused by the oxygen sensor's signal waveform serious noise waveform, the pattern will be somewhat different. By distinguishing the faults corresponding to the different spurious waves and analyzing the signal voltage waveform of the oxygen sensor, the fault area causing the abnormal combustion can be further pinpointed. It is therefore feasible to use an oxygen sensor to detect abnormal engine combustion. 


\section{CONCLUSIONS}

Based on the current situation of energy shortage and environmental pollution in China, the feasibility and superiority of hydrogen as an alternative fuel for engines are analyzed in this paper. However, due to some inherent characteristics of hydrogen, it is easy to cause abnormal combustion phenomenon of pre-ignition, backfire and knock when used as automobile fuel. Based on this, this paper summarizes the generation mechanism, influence factors and the harm of several abnormal combustion conditions. By analyzing the domestic and foreign researches on engine fault and abnormal combustion detection methods, three commonly used detection methods, including ion current method, body vibration method and wide area oxygen sensor method, are summarized.

\section{Conflict of Interest}

The author declares that there is no conflict of interests regarding the publication of this paper.

\section{REFERENCES}

[1] Liu, Z. (2019). Research on flow field and hydrothermal management of proton exchange membrane fuel cells. South China University, Thesis.

[2] Verhelst, S. (2014). Recent progress in the use of hydrogen as a fuel for internal combustion engines. International Journal of Hydrogen Energy, 39(2), 1071-1085. DOI: https://doi.org/10.1016/j.ijhydene.2013.10.102

[3] Yuan, K. (2017). An introduction to early combustion in abnormal combustion of hydrogen internal combustion engines. Automotive Practical Art, 19, 162-164.

[4] Zhang, F. (2017). Effect of split-section injection method on the combustion and performance of hydrogen internal combustion engine. North China University of Water and Electric Power, Thesis.

[5] Ren, T. (2014). Influence of in-cylinder operation parameters on the pressure rise rate and early ignition of hydrogen-fueled engines. North China University of Water Resources and Hydropower, Thesis.

[6] Yuan, K. (2017). An introduction to early combustion in abnormal combustion of hydrogen internal combustion engines. Automotive practical arts, 19, 162-164.

[7] Duan, J., Liu, F., and Sun, B. (2013). Research on the mechanism and control of tempering in inlet tract fuel-injected hydrogen internal combustion engines. Journal of Agricultural Machinery, 44(3), 1-5+37.

[8] Yamin, J. A. A. (2006). Comparative study using hydrogen and gasoline as fuels: combustion duration effect. 30(14), 1175-1187. DOI: https://doi.org/10.1002/er.1213

[9] Zhou, L. (2011). Internal Combustion Mechanics. 3rd edition. Mechanical Industry Press.

[10]Jiang, D. (2001). Combustion and emission of internal combustion engines. Xi'an Jiaotong University Press. 
[11]Jiang, D. (2002). Principles of Higher Internal Combustion Engines. Xi'an Jiaotong University Press.

[12]Zhao, S. (2015). Abnormal combustion of gasoline engines. Agricultural machinery use and maintenance, 2015(1), 40.

[13]Duan, J., Zheng, J., and Yang, Z. (2010). Diagnosis of abnormal combustion in hydrogen engines using radial basis function networks. Journal of North China University of Water Resources and Hydroelectricity (Natural Science Edition), 31(2), 55-58.

[14]Tong, S., Li, H., Y, Z., Hu, Z., and Li, L. (2016). Diagnosis of abnormal in-cylinder combustion based on ion current. Automotive Technology, 2016(9), 18-21+26.

[15] Wu, X., Wang, Y., and Li, F. (2001). A comparison of the ion current method and the body vibration method for the detection of burst vibration. Journal of Xi'an Jiaotong University, 2001(10), 1059-1061+1066.

[16]Wei, H., Hua, J., Feng, D., Pan, M. (2016). A kind of early combustion and Knocking detection and its detection method based on vibrations, CN106762133A, China Patent.

[17]Qi, Z., Zeng, G., Gary, S., Xu, Y., Wang, C., and Zan, X. (2015). Research on active diagnosis strategy for front oxygen sensor response performance of gasoline vehicles. Automotive Engineering, 37(10), 1195-1201.

[18]Dong, Q., Yuan, H., Jian, X., Li, Y., and Jiao, S. (2013). Simulation test of natural gas engine oxygen sensor failure. Journal of Transportation Engineering, 13(3), 6270 .

[19]Fang, W., Ma, Y., Li, Z., and Zhang, C. (2017). Research on detecting abnormal combustion of gasoline engine based on UEGO signal level. Journal of Gansu Agricultural University, 52(4), 188-192.

Article copyright: (C) 2022 Jiahui Liu. This is an open access article distributed under the terms of the Creative Commons Attribution 4.0 International License, which permits unrestricted use and distribution provided the original author and source are credited. 